\title{
COMO A COMPREENSÃO DA DEMANDA APOIA A INOVAÇÃO EM EMPRESAS INDUSTRIAIS?
}

\section{HOW DEMAND UNDERSTANDING CAN SUPPORT INNOVATION IN MANUFACTURING ENTERPRISES?}

\author{
Ana Beatriz Gomes de Mello Moraes ${ }^{1}$; José Vitor Bomtempo Martins ${ }^{2}$ \\ ${ }^{1}$ Federal University of Rio de Janeiro - UFRJ - Rio de Janeiro - Brasil abgmm@uol.com.br \\ ${ }^{2}$ Federal University of Rio de Janeiro - UFRJ - Rio de Janeiro - Brasil vitor@eq.ufrj.br
}

\begin{abstract}
Resumo
A compreensão da demanda, a partir da observação dos hábitos de consumo, é uma prática comum das empresas que atuam nos elos finais das cadeias produtivas. Entretanto, recentemente, a observação das práticas das empresas situadas nas etapas intermediárias da cadeia produtiva permite perceber que estas estão procurando enxergar além de seus mercados diretos. Estas práticas revelam que os movimentos das empresas diferem em função de diversas variáveis, tais como a indústria, porte das empresas, e outros. As intenções ultrapassam a renovação de estratégias comerciais; e parecem relacionar-se à possibilidade de, a longo prazo, participar da evolução da indústria, apoiadas no processo de aprendizagem contínuo e nas competências adquiridas para compreender as necessidades dos clientes. Assim, apesar das diferenças na atuação junto ao mercado final, supõe-se que a economia contemporânea venha encontrando uma situação com teorias pouco estruturadas para explicar tanto a busca pelo aprendizado próximo ao usuário, quanto as perspectivas das indústrias que operam transformações ou manufaturam produtos. Neste sentido, este trabalho pretende se aprofundar na agenda de pesquisa organizada acerca da inovação e construção de competências, procurando aprimorar um quadro analítico que amplie o entendimento destes processos, relacionamentos, e investigando as práticas e os padrões mais freqüentes no esforço de compreensão da demanda final. Os referenciais adotados para desenvolvimento da proposta apoiam-se na Visão Baseada em Recursos (VBR), e nas abordagens que explicam o desempenho competitivo a partir do emprego de seus recursos. As práticas de empresas industriais orientadas para a compreensão da demanda ilustrarão o quadro analítico mencionado.
\end{abstract}

Palavras-chave: inovação, competências para inovar, compreensão da demanda.

\section{Introdução}

As práticas empresariais orientadas para promover ajustes em produtos, com a finalidade de atender a requisitos diversos, tanto de fornecedores quanto de usuários finais, sinalizam que a compreensão da demanda deixou de ser apenas uma variável complementar para a formulação da estratégia no cenário econômico contemporâneo. As diversas contribuições teóricas recentes e, 
principalmente, aquelas oriundas da Economia Industrial ${ }^{1}$ sugerem que não há elemento passivo neste contexto: mercados e empresas interagem continuamente e as relações estabelecidas devem refletir as estratégias adotadas além de, simultaneamente, realimentar com informações o processo em seu ciclo.

Assim, o que antes poderia ser percebido apenas como "complemento" de uma estratégia na visão tradicional da teoria econômica (ou seja: conhecer mais ou menos sobre os mercados diretos e finais), passa a ser visto como algo fundamental na proposta teórica da economia industrial (Kupfer e Hasenclever, 2002). Uma vez que os esforços orientados para melhor compreensão da demanda deixam de ser periféricos no processo, as práticas utlizadas para concretiza-los ganham relevância na medida em que agregam à empresa capacidade para interferir no perfil de sua arena competitiva. O grau de abrangência e a intensidade destas interferências podem variar e ainda, nem sempre, resultar em grandes mudanças. Entretanto, tal característica não elimina a curiosidade em torno "do que está por trás" da prática que foi capaz de causar alguma transformação na dinâmica que existia entre os agentes.

A transformação da qual se fala relaciona-se, na maioria das vezes, à obtenção de vantagens competitivas com ofertas inovadoras e que demonstram forte empenho na conservação e construção de competências, a partir da maior proximidade com a demanda final. Se, para as as empresas que atuam em elos finais da cadeia produtiva, a observação do comportamento do usuário final já se tornou rotina incorporada no design da oferta, para as empresas que atuam nos elos mais intermediários, tal rotina não é trivial. A ausência de trivialidade leva a crer que a previsão de sucesso da empreitada ainda necessite de estudos que busquem conceder credibilidade à analise sem, necessariamente, apoia-la em métodos quantitativos.

Os pensadores da chamada Visão Baseada em Recursos (VBR), e de outras áreas de conhecimento afinadas a ela, defendem que este resultado positivo tem ligação com a articulação de competências internas necessárias para reverter o esforço de aproxinação com os elos subseqüentes da cadeia produtiva em oportunidades de inovação, de identificação de atributos e práticas empresariais valorizadas, e de exploração do potencial pleno das ofertas disponíveis. Sob esta perspectiva, o movimento de reversão indica que a formulação de estratégias bem sucedidas não tem como referência contextos estáticos, mas sim dinâmicos.

A análise destes contextos dinâmicos revela que as decisões estratégicas orientadas para inovação e contrução de competências também devem considerar variáveis que, nem sempre, podem ser quantificadas. Para estas situações, o uso de estudos de casos parece ser um caminho

\footnotetext{
${ }^{1}$ De acordo com Kupfer e Hasenclever (2002, p.5), a economia industrial abriga diversas linhas de pensamento, mas conta com duas correntes teóricas principais denominadas como "abordagem tradicional" (ou mainstream) e "abordagem alternativa" (schumpeteriana/ institucionalista). As duas abordagens, ainda que não encontrem consenso em alguns aspectos, possuem pontos de partida comuns: preocupações com o funcionamento e a coordenação de atividades das empresas em seus mercados.
} 
interessante, principalmente quando a intenção é verificar se uma realidade observada pode ser analisada “(...) tendo uma teoria previamente desenvolvida como referência com a qual os resultados do estudo de caso possam ser comparados (...) caracterizando uma generalização analítica." Yin (1994,p.31). De acordo com Lazonick e Andrea (2004, p.5), este método de generalização difere da generalização estatística na qual os dados de uma amostra formam a bases para as inferências. Os autores esclarecem que o estudo de caso tem um papel relevante em exercícios de construção da teoria (Eisenhrdt,1989), ressaltando que devem ser tomadas algumas precauções no sentido de considerar referenciais já consagrados na literatura, evitando assim generalizações equivocadas.

Assumindo como válida esta recomendação, este trabalho tem por objetivo contribuir para a formação de um quadro analítico para estudar a inovação e a construção de competências, com base em dois pontos principais:

a) A análise de práticas de duas empresas industriais que, com freqüência, são mencionadas na literatura de referência como inovadoras e portadoras de competências distintivas: a GE Plastics e a Praxair/White Martins;

b) A proposta de classificação do comportamento inovativo destas duas empresas na Matriz de Orientações Estratégicas (Berthon, Hulbert e Pitt, 1999) e no Quadro de Análise de Tendências do Crescimento, conforme proposto por Fleck (2003).

Procurando cumprir tal proposta, este trabalho apresenta, na segunda seção, o arcabouço teórico utilizado como referência e as contribuições de alguns autores, afinados à proposta da Visão Baseada em Recursos, consideradas relevantes para o objetivo pauta. A terceira seção trata das propostas teóricas auxiliares para delinear o quadro analítico pretendido. A seção seguinte explora as iniciativas da GE Plastics e Praxair/White Martins na tentativa de ilustrar o esforço de compreensão da demanda final e, por fim, a conclusão, que inclui a discussão de pontos julgados relevantes nas práticas observadas, bem como a retomada do quadro analítico proposto com algumas recomendações.

\section{2 - A Teoria de Referência}

A visão baseada em recursos abriga contribuições de diversos autores e analisa a relação entre os recursos da firma e a vantagem competitiva, sob perspectivas distintas. Nela, os recursos intangíveis são associados a terminologias freqüentemente encontradas nos trabalhos mais recentes sobre o assunto tais como: "competências diferenciais", "capacidades", "capacidades dinâmicas", “ativos especializados", "ativos complementares", e outros. (Kretzer,2002).

De acordo com Barney (1996) e Burlamaqui e Proença (2003), as raízes da VBR são, normalmente, atribuídas aos trabalhos desenvolvidos por Penrose (1959), por Ricardo (1817) e 
Selznick (1957) ${ }^{2}$. Em essência, estes pensadores construíram, em suas obras, argumentos que suportam os postulados centrais da abordagem:

a) "A heterogeneidade dos recursos" (Penrose, 1959): assume que as empresas devem ser vistas como conjuntos de recursos produtivos distintos. A distinção destes conjuntos impede a imitação rápida de opções estratégicas bem sucedidas uma vez que, para imitálas, seria necessário possuir recursos similares.

b) "A imobilidade dos recursos" (Ricardo, 1817; Selznick 1957): alguns recursos não podem ser simplesmente transferidos. Assim, tornam-se ativos únicos, específicos da firma que os desenvolve e, conseqüentemente, escassos.

Nesta perspectiva, a capacidade de articulação de seus recursos internos é a variável determinante do sucesso das firmas. As questões relacionadas à melhor escolha de investimento, à capacidade de erguer barreiras à entrada e de manter rentabilidade elevada por longos períodos de tempo são secundárias. (Teece, Pisano e Shuen, 1997, p. 513). Sobre a escolha dos recursos "certos" e opções estratégicas, o trabalho de Wernerfelt (1984) deve ser considerado como referência. Sua proposição inicial foi a de construir uma análise da posição do estoque de recursos da firma, e as opções estratégicas que estes recursos permitiriam. Assumiu que o esforço de diversificação não deve ser baseado em todos os recursos disponíveis para a firma, mas apenas em alguns que possam ser importantes para obtenção de um posicionamento competitivo diferenciado. Estes recursos específicos e escassos, quando identificados e valorizados, podem capturar rendimentos extraordinários.

Wernerfelt (1984) traz idéias contemporâneas à abordagem tradicional de posicionamento competitivo, na qual se insere Porter (1980) mas distingue-se ao atribuir um papel relevante à interação entre recursos internos e produtos. Estabelece uma relação de causa e efeito, argumentando que um não existe sem o outro. Esta posição torna-se clara logo na introdução de seu artigo "A Resource-based View of the Firm”, quando afirma que “(...) recursos e produtos são dois lados da mesma moeda." (Op. cit., p. 171). Wernerfelt (1984) traz o foco de análise para dentro das fronteiras da empresa, e sugere que a diversificação pode ser um caminho para “(...) capturar rendimentos extraordinários sobre recursos específicos e escassos no mercado"(Teece, Pisano e Shuen, Op. cit., p. 514).

\section{1 - Outras Análises sobre os Recursos Internos como Fontes de Vantagem Competitiva}

\section{Sustentável}

Outros trabalhos propuseram, posteriormente, estruturas para análise dos recursos internos como fontes de vantagens competitivas sustentáveis. Barney (Op.cit., p.142) é um destes autores.

\footnotetext{
2 A citação de Selznick (1957) é particularmente reconhecida em Barney (1996).
} 
Em seu trabalho ${ }^{3,}$ vale-se dos princípios da heterogeneidade e da imobilidade dos recursos, e argumenta que se os recursos: (a) possibilitam que a firma explore oportunidades ou neutralize ameaças; (b) são dominados por poucas firmas que competem em um determinado cenário; (c) têm sua cópia dificultada pelo alto custo, então podem se traduzir em uma força para a firma, ou até em fonte potencial de vantagem competitiva.

Como a definição dos recursos internos pode gerar listas genéricas demais e dificultar a análise do que deve ser considerado ou não, Barney (Op.cit., p.143) os agrupa em quatro categorias: financeiros, físicos, humanos e organizacionais. Diante desta classificação, a avaliação das forças e fraquezas internas de uma firma, em um dado ambiente competitivo, pode ser levada adiante sob a estrutura de análise VRIO (value, rareness, imitability, organization). Nesta perspectiva, os recursos são estudados em função do valor, da raridade, da possibilidade de imitar uma “competência” específica e da forma de organização existente para melhor utiliza-los.

As variáveis consideradas na Análise VRIO não são exclusivas da proposta de Barney (1996). A diferença de sua proposta, provavelmente, deve-se ao questionamento do valor, da raridade, da exclusividade de uma competência ou habilidade e da organização como elementos de um conjunto, no qual a combinação das variáveis pode implicar uma posição competitiva positiva ou não, e em um desempenho econômico normal (lucro econômico ou extraordinário zero) ou acima do normal. A possibilidade de análise estruturada representa uma vantagem. Mas, como toda estrutura que depende de respostas objetivas às questões formuladas, apresenta uma lacuna: a organização é vista como um fator de "ajuste" (Op.cit., p.164).

A observação das práticas de algumas empresas mais orientadas para a inovação através da integração com o mercado, bem como as abordagens teóricas de Penrose (1959), Hamel e Prahalad (1995), Collis e Montgomery (1995), Teece, Pisano e Shuen (1997), dentre outros, sinalizam que a organização é mais do que um fator de ajuste.

Se o ponto de partida for a observação da dinâmica competitiva, as mudanças no cenário sugerem que os players precisam ser mais ágeis. Hamel e Prahalad (1995, p. XII), ilustram a preocupação com a inexistência de soluções para as questões enfrentadas pelas empresas, que passaram a competir em cenários mais dinâmicos, com uma indagação peculiar: “Como (...) concorrentes com recursos aparentemente tão minguados poderiam desafiar com sucesso corporações gigantescas?". Talvez, os concorrentes mencionados não fossem tão "minguados" ou “inexpressivos". Se assim fossem, não deveriam ser considerados tão "ameaçadores" pelos gigantes. Mas, retirando a força das expressões, há uma verdade implícita na indagação: o movimento dos "pequenos" exigiu que os "grandes" dispensassem alguns esforços para repensar

3 A obra citada é o livro do autor, editado em 1996. Entretanto, a proposta da VRIO Framework foi apresentada, anteriormente, em outro trabalho, em 1991. 
suas práticas habituais. Deste processo de revisão, resultou a convicção de que a permanência no cenário competitivo estava ligada ao desenvolvimento ou à revigoração de competências internas, capazes de construir a ponte entre os três espaços de tempo: passado - presente - futuro. (Moraes e Bomtempo, 2004)

O trabalho de Hamel e Prahalad (1995) chama atenção para questões importantes relativas ao tempo de aprendizado, à criação de valor, à compreensão das competências específicas já desenvolvidas e também, quanto às limitações da abordagem concentrada no cenário competitivo externo para orientação estratégica. Entretanto, não concede elementos suficientes para garantir que uma competência essencial identificada seja relevante de fato para mudar a posição da empresa em relação aos seus concorrentes.

Sob este aspecto, Collis e Montgomery (Op.cit., p. 123) posicionam-se de forma crítica. Ao discutir os elementos que tornam um recurso valioso, alertam para a necessidade de aliar a avaliação do valor deste recurso a dados de aceitação de mercado. Em seus argumentos, sustentam que não basta a identificação da competência essencial pois, “(...) se testada, toda empresa terá uma.". Além disto, defendem que ter a competência não é suficiente para garantir a geração de recursos competitivos superiores e distintivos; outros elementos estão envolvidos no processo. Os autores também formulam críticas às abordagens focadas no ambiente externo (Op.cit.,p.118) quanto à capacidade de resposta destas, em ambientes dinâmicos. Defendem que a análise dos recursos internos confere maior segurança tanto na combinação de idéias sugeridas para elaboração de estratégias (como a idéia das competências essenciais, por exemplo), quanto na capacidade para enfrentar as dificuldades de adoção de uma boa estratégia de diferenciação.

\section{2 - Capacitações Dinâmicas}

Sobre a obtenção de vantagens competitivas sustentáveis, Teece, Pisano e Shuen (1997) propõem o conceito Dynamic Capabilities ${ }^{4}$ que, por sua vez, "... procura analisar as fontes de captação e de criação de valor pelas firmas". (Op.cit., p. 509). Esta abordagem reconhece que as teorias formuladas dão suporte para sustentação ou defesa de vantagens competitivas existentes, mas não alcançam o "...entendimento de como e porquê algumas firmas constroem vantagens competitivas em ambientes de rápidas mudanças." (Id.,p.509)

$\mathrm{Na}$ perspectiva das capacitações dinâmicas, as vantagens competitivas têm origem em habilidades e iniciativas próprias das firmas para conjugar, reunir e configurar suas competências

\footnotetext{
4 De acordo com Burlamaqui e Proença (Op. cit., p. 90), a expressão "capacitações dinâmicas", tradução literal da expressão Dynamic Capabilities, foi a escolhida pelos autores para refletir a melhor imagem do conceito proposto originalmente por Tecce, Pisano e Shuen (1997). Na nota sobre o assunto, observam que "...os livros publicados no Brasil têm apresentado a tradução "capacidades dinâmicas", o que aumenta a confusão quanto à intenção dos formuladores do conceito, pois o termo "capacidade" se refere tradicionalmente ao volume máximo de produção que uma empresa á capaz de alcançar”.
} 
internas e externas, e responder aos desafios impostos pelo ambiente mutável. Para tal, é preciso construir $e$ consolidar simultaneamente. Para os autores, as capacitações dinâmicas dependem da existência de um conjunto de variáveis. A identificação de apenas uma ou outra variável não garante que tal habilidade empresarial - "batizada" como "dynamic capabilities" - esteja em sua forma plena. O referido conjunto de variáveis deve contemplar: i) capacidade de apresentar inovações de forma flexível, e com atenção ao timing de mercado; e ii) habilidade gerencial para coordenar e reaplicar competências internas e externas. Quando a soma "(i) + (ii)" oferece um resultado que reflete uma habilidade da organização para atingir a novas e inovadoras formas de vantagem competitiva, considerando a existência de uma trajetória precorrida (path dependency) pela empresa, pode-se dizer que as capacitações dinâmicas foram construídas e sustentam a escalada da empresa em torno de sua estratégia. (Leonard-Barton, 1992)

É interessante notar que, assim como os outros autores aqui citados, os propositores das capacitações dinâmicas não negam o valor das abordagens - chamadas de "paradigmas" no texto original - já existentes, na área da estratégia. Concordam que estas abordagens são complementares, mas registram que, as diferenças entre as propostas, para solução de problemas distintos, podem levar a uma "competição" entre elas (Teece, Pisano e Shuen, Op.cit., p. 526) . Evitar a competição, e trabalhar no sentido da complementaridade, é o mais prudente.

Quando a análise se faz através das capacitações dinâmicas, o salto qualitativo está no peso atribuído à organização no processo de construção de fontes de vantagens competitivas sustentáveis. A organização é entendida como o fator que viabiliza a exploração correta dos recursos internos, e que acolhe os elementos normalmente "externos" às análises estratégicas tradicionais. Sob a perspectiva das capacitações dinâmicas, as fontes de criação e de captura de valor estão nas competências organizacionais, que se refletem através das práticas junto ao mercado, da capacidade de adaptação a novas situações, e na habilidade para dirigir os investimentos corretamente. De forma simplificada, esta idéia indica que deve haver uma estrutura capaz de: (a) Organizar os esforços de identificação das capacitações que podem ser fontes de vantagens competitivas; e (b) Combinar as capacitações, garantindo seu emprego, desenvolvimento e proteção adequados.

As abordagens até então mencionadas reconhecem que cpacitações, conhecimento e informação possuem valor estratégico para as organizações. Entretanto, de acordo com Nonaka e Takeuchi (1997,p.6) “(...) A constatação de que o conhecimento é o novo recurso competitivo atingiu o ocidente como um relâmpago. Porém, toda essa conversa sobre a importância do conhecimento - tanto para as empresas quanto para os países - pouco nos ajuda a compreender como se cria o conhecimento." . Alertam para o fato de que as atenções sobre negócios e sociedades não resultaram em compreensão dos mecanismos e processos que permitem a criação do 
conhecimento. No máximo, o que se conseguiu foi iluminar o conhecimento explícito (ou seja, aquele que resulta da sistematização de informações e que é formal).

Deixam claro que todo processo não pode ocorrer sem os indivíduos. Eles são "depósitos" do chamado conhecimento tácito (ou seja, aquele que é pessoal, e difícil de ser formalizado) que, de acordo com a abordagem proposta, é o combustível da inovação. Entendem que a inovação (...) "Não é responsabilidade de poucos eleitos - um especialista em pesquisa e desenvolvimento, planejamento estratégico ou marketing - mas sim de todos na organização.” (Op. cit., p. 10).

O trabalho dos autores tem uma proposta audaciosa: construir uma teoria sobre a criação do conhecimento organizacional desenvolvida no Japão. Valem-se das abordagens existentes para sustentar diversos argumentos e deixam uma importante contribuição para compreensão de como o conhecimento organizacional se forma: a chamada espiral do conhecimento.

A espiral reúne os modos de conversão do conhecimento, as formas pelas quais o conhecimento tácito se transforma em conhecimento explícito e relacionam todos esses conceitos com as condições capacitadoras para a criação do conhecimento organizacional no Modelo de Cinco Fases do Processo de Criação do Conhecimento (Op. cit., p.96). A partir deste modelo, os modos de conversão e, especialmente, o modo chamado de internalização parecem ganhar clareza e comprovar que o chamado conhecimento organizacional resulta de interações diversas, inclusive com pontas externas à empresa: organizações colaboradoras, usuários e mercados. A Figura 1 ilustra o modelo mencionado. Deve-se ressaltar que, como todo modelo teórico, este também deve ser interpretado como uma situação ideal e não representa, necessariamente, a realidade das empresas.

Figura 1 - Modelo de Cinco Fases do Processo de Criação do Conhecimento. Nonaka e Takeuchi, 1997, p. 96.

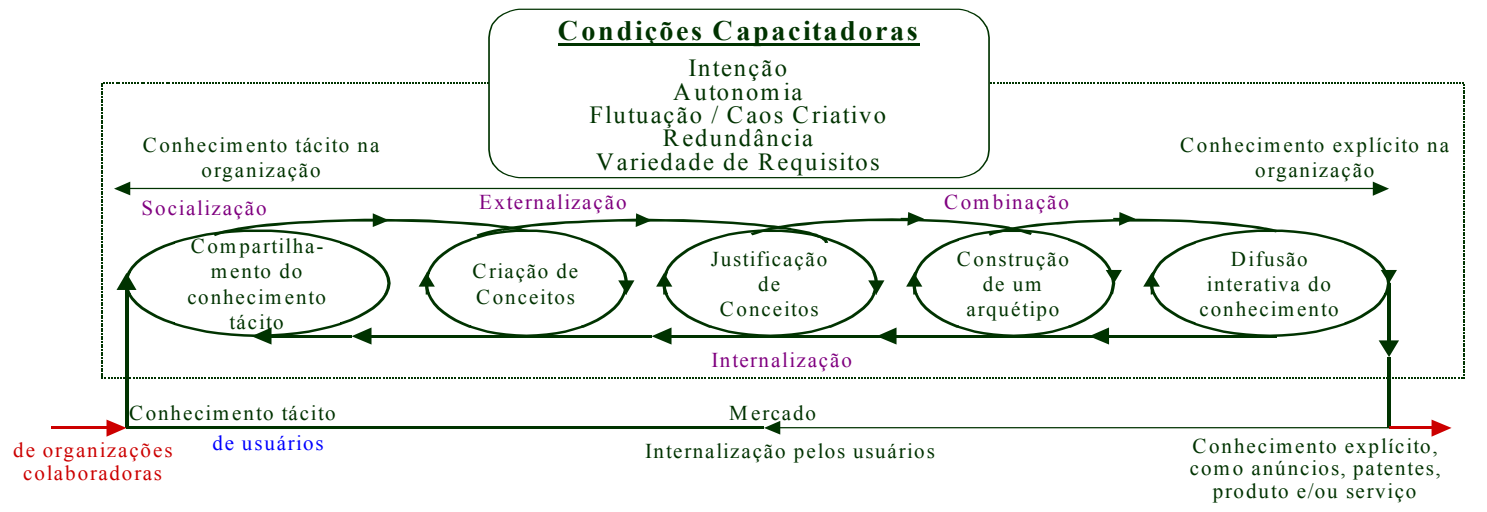

Fonte: Nonaka e Takeuchi, (Id., p. 96)

\section{3 - Propostas Auxiliares para Análise}

Para complementar o quadro analítico proposto, sugere-se a inclusão da Matriz de Orientações Estratégicas (Berthon, Hulbert e Pitt, 1999) e do Quadro de Análise de Traços 
Organizacionais (Fleck, 2003). As duas abordagens, apesar de terem sido desenvolvidas com objetivos diferentes, são complementares e permitem no caso em tela uma maior clareza na observação dos casos estudados.

\section{1 - A Matriz de Orientações Estratégicas}

Berthon, Hulbert e Pitt (1999), elaboraram a chamada Matriz de Orientações Estratégicas considerando que as firmas atuam, tradicionalmente, segundo duas orientações principais: a orientação para o mercado (ou orientação para o cliente) e a orientação para a inovação tecnológica. Quando as empresas orientam-se para o mercado, o sucesso da organização é entendido um resultado direto da correta identificação das necessidades e desejos do mercado alvo, e da oferta de produtos e serviços alinhados às necessidades identificadas. Por outro lado, se a orientação se dá para a inovação tecnológica, o sucesso resulta de ofertas tecnologicamente superiores, com produtos e serviços capazes de provocar o interesse, agregando bom desempenho, facilidades, qualidade e valor.

De acordo com a proposta, tanto uma orientação quanto a outra - para o mercado ou para inovação - devem ser consideradas dois blocos distintos, mas que guardam interação entre si. Esta interação pode ser facilitadora ou inibitória em função da forma como as orientações são traçadas e implementadas pela firma. Assim, como a questão do alinhamento é fundamental para o resultado, propõem o uso de uma matriz (Figura 2), dentro da qual as orientações são posicionadas em quadrantes em função de algumas características visíveis em suas práticas de mercado.

Figura 2 - Matriz de Orientações Estratégicas

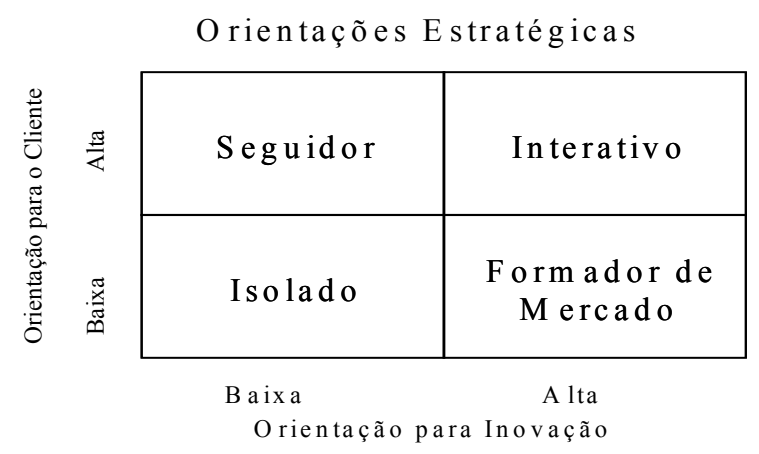

Fonte: Berthon, P., Hulbert, J., Pitt, L. To Serve or to Create? Strategic Orientations towards Customers and Innovation. California Management Review, vol.42, n. 1, Fall 1999.

As formas de atuação relacionam-se com a orientação da firma para o cliente ou para a inovação. Cada um dos modos de operação tem suas características genéricas listadas abaixo:

- "modo isolado": o foco das atenções é o lado interno da própria organização, 
havendo pouca comunicação entre a inovação e o mercado.

- "modo seguidor": a organização movimenta-se segundo demandas do mercado mapeadas através de pesquisas de marketing (formais ou informais), tanto para o desenvolvimento de novos produtos ou serviços, quanto para o refinamento destes.

- "modo formador de mercado": a tecnologia orientada para inovação é o foco principal. Neste modo, a firma acredita que as necessidades - e até mesmo a natureza da demanda - dos clientes podem ser moldadas, tornando disponível uma tecnologia superior. Aqui, a firma tanto pode tentar definir de novos usos, quanto influenciar as preferências.

- "modo interativo": é o modo no qual se dá o "diálogo" entre o usuário (com suas expectativas e necessidades) e a tecnologia disponível. Nesta forma, as partes interagem para alcançar um ponto comum, trocando informações sobre os processos de cada uma das partes. Os autores classificam esta orientação como "um modo de negociação interativa" (Op. Cit., p. 47) muito utilizado nos mercados industriais.

De fato, o quadrante do modo interativo é o que apresenta melhor relação custo/ benefício para os segmentos que mais sofrem com necessidades contraditórias impostas pelo ritmo competitivo, como a coexistência de estruturas adaptáveis a novas realidades e produtos de curto ciclo de vida, que exigem elevadas somas de investimento. Nele, inovação e necessidades/ expectativas dos clientes são contempladas proporcionalmente, permitindo que a empresa faça uso de seus recursos internos - segundo propostas da VBR - para atender e satisfazer às demandas de mercado.

\section{2 - O Quadro de Análise de Tendências do Crescimento}

Segundo Fleck (2003), estudos sobre duas empresas longevas - GE e Westinghouse constatam que alguns comportamentos podem ser observados sistematicamente nas práticas organizacionais ao longo de sua existência. A autora classifica estes comportamentos como "traços organizacionais" que refletem uma “(...) resposta da empresa a um desafio gerencial associado ao processo de crescimento organizacional" (Op.cit., p. 26). A reação da empresa ao desafio determina, sob esta perspectiva, a propensão à “autoperpetuação" ou à “autodestruição".

Nos estudos longitudinais foram identificados sete categorias de traços, sendo quatro destes relativos a aspectos internos da organização, e os outros três associados aos negócios. O quadro, ilustrado na Figura 03, sintetiza as características destes traços. A princípio, as respostas aos desafios que indicam o caminho da autoperpetuação são as que mais se afinam à proposta de compreender como os processos de inovação e de construção de competências dão suporte ao aprendizado organizacional. 
Figura 03 - Quadro de Análise de Tendências do Crescimento

\begin{tabular}{|c|c|c|c|}
\hline Categoria do traso & Desafio & Aulodestruiģق̆ & Autoperpetu3ģ̧ুo \\
\hline \multicolumn{4}{|l|}{ Orientaciâno internu } \\
\hline Organizaşa & 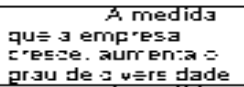 & $\begin{array}{l}\text { Cragmentagâc } \\
\text { isutonomia das } \\
\text { :ar.esi }\end{array}$ & 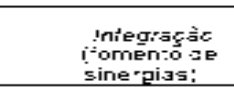 \\
\hline $\begin{array}{l}\text { Albcaçä́ de } \\
\text { recursos }\end{array}$ & 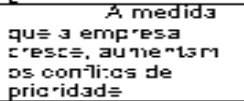 & 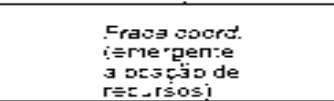 & 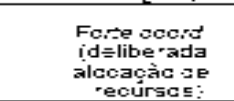 \\
\hline $\begin{array}{l}\text { Resoluç3̆o de } \\
\text { problem }\end{array}$ & 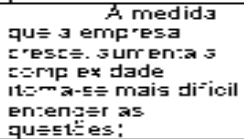 & 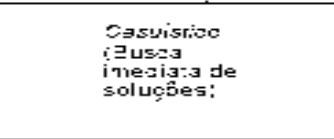 & 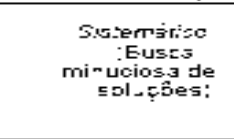 \\
\hline $\begin{array}{l}\text { Farmaçâ de de } \\
\text { hierarquia gerencial }\end{array}$ & 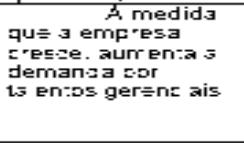 & 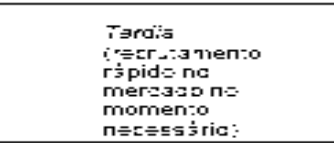 & 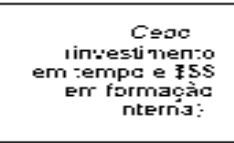 \\
\hline \multicolumn{4}{|l|}{$\begin{array}{l}\text { Orient3ç30 a0s } \\
\text { negócios }\end{array}$} \\
\hline Empretendedorismo & $\begin{array}{l}\text { Fonento } \\
\text { de niciativas } \\
\text { empreendedoras } \\
\text { no se o da } \\
\text { empresa }\end{array}$ & 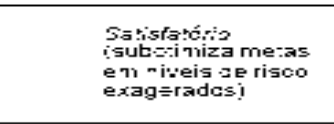 & 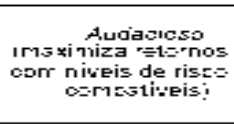 \\
\hline $\begin{array}{c}\text { Mativagăes para } \\
\text { expansäo }\end{array}$ & 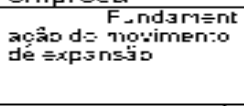 & 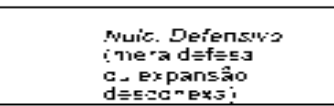 & 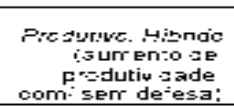 \\
\hline $\begin{array}{l}\text { Gestăo da } \\
\text { mudanģa }\end{array}$ & 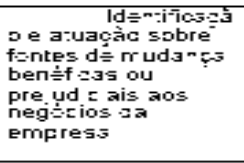 & 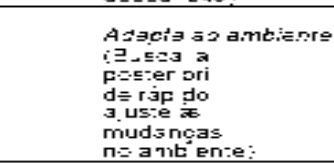 & 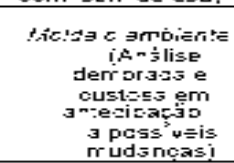 \\
\hline
\end{tabular}

Fonte: Fleck, D. Revista Eletrônica Economia e Conjuntura, Abril / 2003, p.27

\section{4 - As Práticas da GE Plastics e White Martins}

Algumas iniciativas de duas empresas empresas industriais - GE Plastics e White Martins foram consideradas para ilustrar o caráter estratégico dos esforcos voltados para a compreensão da demanda.

\section{1 - O Caso da GE Plastics 5}

$\mathrm{Na}$ tradição dos grupos criados a partir de uma base de P\&D, a divisão GE Plastics (GEP) foi criada pela GE em 1965 como uma nova linha de produtos GE criada a partir de seus laboratórios. A GEP conta com dois pontos particularmente fortes ao ser criada: patentes bem protegidas em relação a dois polímeros descobertos nos anos 1950, e uma rica experiência como utilizadora de materiais sintéticos. O primeiro ponto - a posse de patentes como vantagem competitiva - é clássico na história da química de síntese já que não são raros os produtores de polímeros que consolidaram suas posições na indústria a partir de patentes bem protegidas. $\mathrm{O}$ segundo ponto, entretanto, constitui uma originalidade na história da indústria de polímeros. A GEP se apresenta no mercado com uma cultura ausente nos produtores tradicionais de plásticos: a de

\footnotetext{
${ }^{5}$ O caso GE Plastics é baseado em Bomtempo, 1994.
} 
buscar a compreensão da utilização. Essa capacidade se torna ainda mais valiosa quando se leva em consideração que a dinâmica da indústria de polímeros, a partir dos anos 1950, havia, de certa forma, afastado os produtores de uma compreensão precisa das necessidades dos usuários finais.

As condições de utilização dos dois polímeros descobertos pela GEP eram claramente diversas daquelas da maioria dos polímeros já comercializados. Nessa época o segmento de plásticos de engenharia ainda se encontrava num estágio inicial de desenvolvimento. Os níveis de performance dos polímeros lançados pela GEP abriam campos de utilização totalmente novos. O automóvel, por exemplo, empregava uma quantidade relativamente pequena de plásticos e quase sempre em peças de importância secundária. Limitava-se em geral ao revestimento interior dos carros. Assim sendo, o sucesso da nova geração de polímeros, ditos de engenharia, dependia claramente da criação de condições que possibilitassem a aprendizagem dos novos materiais pelos utilizadores. Seria então necessário organizar de uma forma renovada a comercialização de modo a revigorar a interação entre o produtor de material e o utilizador final. Com esta interação, os utilizadores finais poderiam aprender com material, condição prévia para a substituição dos materiais tradicionais em peças de importância técnica considerável, principalmente quando essa substituição pode exigir um novo esforço de concepção da peça ou, em alguns casos, do próprio objeto.

A GE encontrava-se em boas condições para atender essa exigência. Tratava-se na realidade de valorizar sua experiência no desenvolvimento de produtos estritamente definidos segundo as necessidades de uma utilização específica. Nos anos 60 a estrutura organizacional do grupo GE era notável por sua descentralização. Acrescente-se que o departamento de plásticos era, tradicionalmente, dedicado ao atendimento interno do grupo, principalmente no que se refere à solução de problemas ligados à evolução e adaptação dos materiais aos seus produtos. Pode-se supor que as competências de natureza organizacional desenvolvidas pela empresa foram, na realidade, o fruto de um aprendizado no interior do próprio grupo GE.

A criação da divisão GEP representou a possibilidade de desenvolver as competências organizacionais acumuladas pelo grupo tendo em vista a exploração das potencialidades dos novos produtos e seus mercados. É sobre essas competências que GEP constrói o seu enfoque orientado para o mercado - mais precisamente para o utilizador final - em oposição ao enfoque orientado para o produto, tradicional na indústria. $\mathrm{Na}$ condição de utilizador final de polímeros, GE tinha aprendido a fazer chegar até à $\mathrm{P} \& \mathrm{D}$ as exigências do produto final, a tratá-las e a encontrar as soluções adequadas. A GEP se empenhou então em explorar no mercado os resultados dessa aprendizagem.

Os Centros Técnicos, criados nos anos 70, representam a resposta dada pela GEP ao problema da tomada de conhecimento das necessidades dos clientes. Eles representam um elemento 
essencial da estratégia pela qual a GEP construiu sua presença na indústria. Os Centros Técnicos são mais tarde completados pelos Centros de Desenvolvimento, constituindo uma rede de ligação da empresa a seus clientes. Os mecanismos desenvolvidos pela GEP permitem a interação com utilizadores finais, transformadores, fabricantes de equipamentos e moldes e outros. Eles são essenciais para que se possa compreender como a GEP construiu sua presença na indústria. A organização dos centros comporta, habitualmente, equipes de engenheiros trabalhando sobre os problemas específicos de determinadas indústrias. A GEP escolheu inicialmente o automóvel como alvo. Este foco levou, principalmente nos anos iniciais da empresa, à presença de engenheiros da GEP dentro das fábricas e laboratórios dos utilizadores.

A elaboração de protótipos e objetos conceituais (o automóvel Vector e o projeto Living Environments são alguns exemplos que merecem citação) constitui um outro recurso do qual a GEP lança mão freqüentemente na abordagem das indústrias utilizadoras. Entretanto, a vocação fundamental dos CT e CDA é de assegurar um serviço de assistência técnica aos clientes de modo a promover um esforço permanente de desenvolvimento de aplicações. Assim, é oferecido um conjunto de serviços essenciais para a evolução de seus produtos (laboratórios, recursos para realização de ensaios e testes, laboratórios de moldagem, realização de protótipos).

$\mathrm{Na}$ GE Plastics, a estrutura organizacional implantada para gerir as relações com as indústrias utilizadoras concede sustentação à análise. Estas relações não foram consideradas apenas quando envolviam os clientes imediatos, mas também o utilizador final, ao qual se dirige o produto. Como regra geral, um produtor de polímeros $^{6}$ vende seus produtos a transformadores, que são então seus clientes. Mas, esses dedicam-se apenas, na maior parte dos casos, a fabricar peças ou objetos que serão montados pelas indústrias a jusante em produtos de consumo final.

Nessas condições, GEP então organizou sua estrutura comercial conferindo-lhe um caráter mais técnico e procurando garantir a criação de um canal de comunicação com os transformadores e os utilizadores finais. Aos últimos, isso permitiu tanto aprender a utilizar os plásticos, quanto fazer chegar suas necessidades aos produtores.

O modelo organizacional e relacional desenvolvido pela GEP, nos anos 70 e 80, e consolidado nos anos 90, foi seguido pelos competidores que também estruturaram suas empresas de forma semelhante na abordagem dos segmentos finais da cadeia produtiva. Ainda que existam outros competidorees, GE Plastics tem mantido posicionamento privilegiado na indústria cuja construção se apoiou fortemente nos mecanismos de compreensão da demanda implementados pela empresa.

\footnotetext{
${ }^{6}$ Os polímeros são produtos de base da industria petroquímica e incluem os plásticos e outros produtos similares (as fibras, as borrachas sintéticas) do ponto de vista de sua estrutura química.
} 


\section{2 - O Caso da Praxair / White Martins}

A White Martins, fundada em maio de 1912, em São Cristõvão, no Rio de Janeiro, foi a primeira fábrica de oxigênio do Brasil e, atualmente, é subsidiária da empresa norte americana Praxair na América do Sul, com atuação em mais oito países nesta parte do continente: Argentina, Venezuela, Colômbia, Chile, Peru, Uruguai, Bolívia e Paraguai.

A Praxair é uma das três maiores empresas de gases industriais do mundo, com operações em 40 países e vendas anuais em torno de US\$ 5 bilhões. A White Martins é empresa líder ${ }^{7}$ no mercado de gases industriais e medicinais na América Latina e responde por $12 \%$ do total de vendas da Praxair. Abastece empresas de diversos setores, dentre eles petroquímica, metalmecânica, siderurgia, papéis, vidros, alimentos e bebidas. Seu portfólio de produtos inclui gases atmosféricos (oxigênio, nitrogênio e argônio), gases de processo (gás carbônico, acetileno, hidrogênio, misturas para soldagem), gases especiais e medicinais, cilindros de aço sem costura e equipamentos para aplicação, transporte e armazenamento de gases.

Em sua declaração de missão, a empresa atesta que a tecnologia tem o papel de garantir competitividade, sustentar seu crescimento além de adicionar valor para os clientes. A principal orientação é a de oferecer soluções, seja através de serviços ou de tecnologias de alta qualidade, para os diferentes segmentos industriais com os quais se relacionam. A criação de centros de tecnologia, em diversas unidades da Praxair ao redor do mundo, para pesquisa de novas aplicações e desenvolvimento de novas tecnologias, indica que está interessada em aprimorar a forma de tratar o produto junto ao seu mercado direto, e em descobrir novas aplicações para os mercados que não são diretamente ligados a ela na cadeia produtiva.

No Brasil, o Centro Tecnológico Rio da White Martins é um dos centros de desenvolvimento de tecnologia da Praxair. A proposta de criação dos centros focados em pesquisa faz parte da estratégia de desenvolvimento tecnológico da empresa. No centro brasileiro, além de um grupo de engenheiros dedicados ao desenvolvimento de equipamentos para aplicações, existem instalações para treinamento de clientes e laboratórios para teste e desenvolvimento de aplicações em diversas áreas, tais como metalurgia, refigeração de alimentos, gazificação, tratamento de efluentes, combustão e controle de qualidade. Para uma empresa de gases industriais e medicinais, que podem ser considerados commodities por natureza, a prática da White Martins vai além do esperado por não ter como preocupações básicas somente o volume de produção ou a ampliação do leque de ofertas para atender um número maior de mercados. Tal conduta reflete a política da controladora e, provavelmente, só se tornou concreta pela injeção de capital para explorar a vocação interna de atendimento ao mercado nacional, nos ramos em que já atuava.

\footnotetext{
${ }^{7}$ Segundo dados da Gazeta Mercantil de julho de 2004, a empresa conta com 171 unidades na Américado Sul e seu market share, no Brasil, é de $65 \%$.
} 
O centro de tecnologia brasileiro simboliza, em um primeiro momento, que há consciência quanto à necessidade de investir em desenvolvimento de novas tecnologias e aplicações para sustentar o crescimento. No segundo momento, o formato interativo do Centro Tecnológico Rio (com instalações para treinamento de clientes, laboratórios para teste e desenvolvimento de aplicações e profissionais ocupados com novos produtos e equipamentos), assim como nos demais centros ao redor do mundo, indica que as demandas dos clientes podem inspirar a criação de novas soluções e, conseqüentemente, novas ofertas no futuro. Ainda que não se disponha de informações públicas quanto aos resultados, a manutenção dos centros tecnológicos é um indicador de que esse tipo de iniciativa gera benefícios para a empresa.

Apesar de sua imagem não estar construída com um foco específico na oferta de soluções para somente uma determinada área, não se pode desconsiderar a ligação histórica da White Martins com o fornecimento de gases medicinais. Esta forte associação fez com que seu reposicionamento como provedora de soluções em saúde, desenvolvendo soluções para otimizar recursos hospitalares, surgisse sem causar qualquer reação de surpresa por parte de seu mercado direto. Na realidade, a ligação entre a história e a proposta de reposicionamento apresenta-se quase que como uma “evolução natural” do acúmulo de experiência e do conhecimento acerca das necessidades da área, o que pode ser observado por dois aspectos: (1) A área de healthcare foi uma das que mais cresceu em resultado de vendas para a controladora Praxair, em 2004; e (2) Segundo dados apresentados na Morgan Stanley Basic Materials Conference, em fevererio de 2005, a área de healthcare teve suas vendas totais contabilizadas em US\$740 milhões. Deste total, 20\% foram gerados pelas vendas na América do Sul e os $80 \%$ restantes foram, respectivamente, gerados pela América do Norte (64\%) e Europa e Ásia (16\%). De acordo com o Relatório Anual de 2004 de sua controladora (a Praxair), quatro mercados-alvo tiveram seus resultados em vendas substancialmente elevados: Hidrogênio (para atendimento da demanda em combustíveis limpos), Healthcare (pela aquisição das quatro maiores empresas fornecedoras na área de healthcare doméstico), Eletrônicos (com serviços orientados para supply-chain e ciências de materiais de alta performance para indústriua de semicondutores), e China (em parcerias com clientes globais que estão desenvolvendo três corredores industriais). O aumento das vendas no mercado de healthcare é o segundo maior dentre os demais mercados e é coerente com a estimativa de uma "vocação própria" da subsidiária brasileira nesta área. O Quadro 01 ilustra tais resultados na Praxair.

Quadro 01 - Mercados e Aumento no Total de Vendas

\begin{tabular}{|l|c|}
\hline \multicolumn{1}{|c|}{ Mercado } & Aumento no Total de Vendas \\
\hline Hidrogênio & $38 \%$ \\
\hline Healthcare & $26 \%$ \\
\hline Eletrônicos & $18 \%$ \\
\hline China & $27 \%$ \\
\hline \multicolumn{2}{|c|}{ Fonte: Annual Report 2004 - Praxair - Consultado em www.praxair.com } \\
\hline
\end{tabular}


O mesmo relatório divide os resultados da Praxair em vendas para diversos mercados atendidos. Os resultados são originalmente apresentados em termos de percentual de vendas total para cada mercado (e suas subdivisões) além de procurar demonstrar os benefícios dos clientes com a oferta em questão. Para os fins deste trabalho, apenas os resultados por mercado e suas grandes subdivisões serão ilustrados no Quadro 02.

Quadro 02 - Mercados, Grandes subdivisões e Participação no Total de Vendas

\begin{tabular}{|c|l|c|}
\hline Mercado & \multicolumn{1}{c|}{$\begin{array}{c}\text { Subsivisões } \\
\text { narticipação } \\
\text { Vendas (\%) }\end{array}$} \\
\hline Manufatura & $\begin{array}{l}\text { Aplicações para metalurgia; Tratamento térmico; Produção de vidro; Tratamento de águas; Celulose } \\
\text { e papel; Impressão }\end{array}$ & 21 \\
\hline Metalurgia & Processos e serviços diversos & 16 \\
\hline Energia & Refino de petróleo; Produção e recuperação de óleo e gás; Utilidades & 12 \\
\hline Variedades & Desenvolvimento de soluções diversas (atendimento de necessidades de pequenos mercados) & 12 \\
\hline Healthcare & Homecare; Hospitalares & 11 \\
\hline Químicos & Biotecnologia, ciências da vida e farmacêuticos & 10 \\
\hline Eletrônicos & $\begin{array}{l}\text { Gases de processo; Serviços de infra-estrutura para fabricação; Soluções para ferramentas de } \\
\text { processo }\end{array}$ & 7 \\
\hline Alimentos e Bebidas & Serviços diversos & 7 \\
\hline Aeroespacial & $\begin{array}{l}\text { Manufatura espacial e de propulsão; Operação e fabricação de equipamentos para aeronaves; } \\
\text { Aeronaves e espaçonaves }\end{array}$ & 1 \\
\hline
\end{tabular}

Fonte: Elaboração própria a partir de dados do Annual Report 2004 da Praxair.

\section{5 - Conclusão}

\section{1 - A Compreensão da Demanda e Inovação: Algumas Lições da Prática}

A compreensão da demanda requer, dentre outras práticas, esforço de aproximação entre produtores e usuários para a obtenção de resultados positivos e, possivelmente, inovadores. Entretanto, conforme observado por Bomtempo e Ughetto (2001, p.3), este esforço “...não trata apenas de mobilizar a noção de proximidade para estudar as relações entre as empresas e seus clientes. (...) a compreensão que se tem da proximidade - e dos mecanismos de aproximação que ela implica - necessita ser aprofundada.”. As abordagens acerca da proximidade organizacional com seus clientes estão, normalmente, orientadas para enxergar as redes nas quais se dão as interações e, mais especificamente, quais são as partes da interação em si. Entretanto, esta perspectiva não esgota dois aspectos importantes para que se avalie como obter resultados efetivos: (1) como a empresa desenvolve a proximidade com os elos que apontam para o uso final (sem restringir esta análise às modalidades de "encontro" ou de interação entre indivíduos) e, (2) o que esta proximidade permite incorporar, como ganhos em termos de conhecimento ou construção compartilhada de produtos. O foco sobre a indústria utilizadora exige a implementação de uma estrutura organizacional apropriada. Esta implementação deriva de um processo de adaptação da firma que, normalmente, é observado segundo duas dimensões complementares: a dimensão interna à firma e a dimensão das relações entre a firma e seu ambiente. A primeira é a dimensão 
organizacional propriamente dita e a segunda, a dimensão relacional.

No interior da firma, os efeitos organizacionais das relações com as indústrias utilizadoras, ou com o usuário final, vão na direção de um questionamento da forma tradicional das relações entre as atividades funcionais de base (a P\&D, a produção e o marketing). $\mathrm{O}$ envolvimento das três funções no processo de desenvolvimento é uma preocupação das empresas que têm como função crítica a capacidade de criação permanente de novos produtos e, nestes casos, a formação de equipes interfuncionais de desenvolvimento é um meio freqüentemente citado.

No que se refere às relações entre a firma e seu ambiente, em particular os segmentos a jusante, a construção de relações se torna tão importante quanto a venda de produtos. Assim, não se trata apenas de oferecer serviços associados ou de agregar valor, sob a perspectiva tradicional de marketing. Trata-se de buscar mecanismos relacionais para internalizar a demanda e aprender com ela. Isto significa concentrar o processo de aprendizagem em indústrias utilizadoras nas quais pretende se especializar, ou ainda, desenvolver novas aplicações em conjunto com seus usuários, deixando clara a intenção de firmar um compromisso de longo prazo com estes elos a jusante. $\mathrm{O}$ processo de aprendizagem resulta de uma interação capaz de permitir a circulação de um fluxo de informações qualitativas, e até mesmo, a cooperação direta entre os agentes econômicos. Tal situação está longe de ser obtida por um simples ato de vontade declarada e sua implementação caracteriza a evolução da estrutura organizacional das firmas no ambiente atual.

Na realidade, a idéia de uma empresa voltada para o mercado não passa de uma noção vazia se ela não se traduz em práticas que revelem a intenção. Do ponto de vista de um produtor de materiais, a implantação de um marketing por indústria utilizadora, no lugar do tradicional marketing por produto, pode representar uma mudança de fundo. A significação econômica dessa modificação organizacional ultrapassa o quadro de uma estratégia comercial.

\section{2 - Considerações Finais Sobre o Quadro Analítico e Recomendações}

Os relatos sobre a divisão da General Electric - a GE Plastics (BOMTEMPO, 1994) - e a subsidiária da Praxair na América do Sul - a White Martins - ilustraram, resumidamente, formas distintas de evolução de estruturas organizacionais apoiadas na implementação de mecanismos relacionais. Tais mecanismos indicam que a antecipação à demandas próximas, ou ainda não declaradas, foi percebida como relevante pelas empresas não só pela possibilidade de "aprender", mas também, pela possibilidade de reforçar competências para inovar.

A proposta de contribuir para a formação de um quadro analítico que amplie a compreensão da inovação e da construção de competências, a partir do arcabouço teórico da VBR, acrescido da Matriz de Orientações Estratégicas (Berthon, Hulbert e Pitt, 1999) e do Quadro de Análise de 
Traços Organizacionais (Fleck, 2003), revelaram que:

a) A orientação para captação de valor a partir da dimensão relacional torna-se visível pela análise através da Matriz de Orientações Estratégicas e as duas empresas, em linhas genéricas, parecem ajustar-se ao modo de operação interativo em função de características das práticas empresariais registradas, tais como: diálogo entre usuários e recursos tecnológicos disponíveis (através dos CT's da GE Plastics e dos Centros de Tecnologia da Praxair/White Martins) ${ }^{8}$, troca de informações e, de forma explícita na Praxair/White Martins, negociações interativas pelo desenvolvimento de soluções específicas para atendimento de pequenos mercados.

b) O foco das práticas não é a obtenção de resultados imediatos, mas sim participar da evolução da indústria. Tal aspecto torna-se mais nítido com o Quadro de Análise de Tendências do Crescimento, principalmente nos traços associados à orientação interna: organização, alocação de recursos, resolução de problemas e formação da hierarquia gerencial. Nesses traços, as informações indicam que a resposta aos desafios se dá no sentido da autoperpetuação nas duas empresas. Quando a análise se dá na esfera dos traços associados à orientação aos negócios, tanto a GE Plastics quanto a Praxair/ White Martins também enquadram-se como empresas que caminham no sentido da autoperpetuação pelo esforço de manter o fomento de iniciativas empreendedoras no seio da empresa, por manter os movimentos para expansão de forma produtiva, e pela tentativa de moldar o ambiente, através do desenvolvimento de novas aplicações de forma interativa.

c) A relação entre estruturas organizadas para explorar os recursos internos das empresas e a capacidade de inovação (em conjunto com o aproveitamento de oportunidades nos mercados de atuação) torna-se mais evidente com a observação do esforço de aproximação da demanda final para o desenvolvimento de novos produtos.

d) Vistos de forma conjunta, o quadrante do "Modo Interativo" e as respostas orientadas para autoperpetuação parecem conjugar a situação ideal das práticas empresariais na busca da chamada vantagem competitiva sustentável.

Neste sentido, recomenda-se que futuros trabalhos procurem integrar os dois intrumentos com o objetivo de verificar como as práticas empresariais se ajustam a parâmetros específicos. O exercício poderá ampliar as alternativas voltadas para o entendimento da inovação e dos processos de desenvolvimento de tecnologias, apoiados na compreensão da demanda final.

\footnotetext{
${ }^{8}$ A criação de Centros Técnicos é atualmente na indústria química uma das manifestações mais claras do esforço das firmas para superar as formas tradicionais de interação com os segmentos a jusante. O objetivo declarado é de oferecer produto et serviços mobilizando da forma a mais ampla possível as competências da firma.
} 


\begin{abstract}
The main objective of this study is to enhance the understanding of innovation process in those firms that are traditionally located in the early (or in the intermediate) stages of the productive chain. The efforts to enlarge the focus to observe what is going on beyond their direct markets reveal that these firms need to know more about end users and that this movement is not only related with the intention of building a new market strategy. Probably, these companies intend to do more than revitalize their commercial strategies and, accordig to the observation of firms' practices, a "good job" may be a result from the hability to organize resources, and to exploit demand understanding informations to shift their innovation practices. Developed studies revealed that this research subject transits through diverse areas of knowledge, most of them with unclear boundaries, and that concentrated efforts on being closer to the end user, and on establishing networks, seem to be more related to the value of learning provided by these interactions than to the simple exploitation of an opportunity (market trends or idle capacity, for example). From these assumptions, this work tries to deepen the research agenda structured around mechanisms or practices to understand the demand of end users, through shortening the distance between them and upstream segments of the productive chain, and to evaluate the function of these mechanisms, verifying if the efforts oriented for demand understanding follow any standard. The investigation uses the Resource Based View (RBV) (and some correlated theories that explain competitive performance through resouces' use) as support to build its theorectical framework, and highlights some manufacturing firms practices that seem to be oriented to straiten the relationship between them and end users.
\end{abstract}

Key-words: innovation, competences to innovate, demand understanding.

\title{
Referências Bibliográficas
}

BARNEY, J., Gaining and Sustaining Competitive Advantage. Addison - Wesley. 1996.

Berthon, P., hulbert, J., PITT, L. To Serve or to Create? Strategic Orientations towards Customers and Innovation. California Management Review, vol.42, n. 1, Fall 1999.

BOMTEMPO, J V, UGHETTO P., Proximité à l'égard du client et compétences de la firme, Troisiemes journées de la proximité, Paris, 13-14 dezembro 2001.

BOMTEMPO,J.V., Innovation et organisation: le cas de l'industrie des polymères. Paris: CERNA/Ecole des Mines de Paris. 1994. Tese (Doutorado em Economia).1994

BURlAMAQUI, L., PROENÇA, A. Inovação, Recursos e Comprometimento: em Direção a uma Teoria Estratégica da Firma. Revista Brasileira de Inovação. v.2, n.1, p.79-110. 2003.

COLliS, D.J., MONTGOMERY, C.A., Competing on Resources: Strategy in the 1990's. Harvard Business Review. July- August. p. 118-128, 1995.

EISENHARDT, K. M., Building Theories from Case Study Research, Academy of Management Review, v.14, n.4, p.532-550, 1989.

cross ${ }^{\text {ef }}$

FIGUEIREDO. A. White Martins firma parceria para gestão hospitalar. Gazeta Mercantil - Gazeta do Brasil. Edição de 8/7/2004, p.14.

FLECK, D. Desafios do crescimento corporativo e suas consequências para a perenidade da empresa. Análise da Conjuntura Macroeconomica, Ano 3, n.39, p.26-31,Abril / 2003. Hamel, C., Prahalad, C.K., Competindo pelo Futuro. Rio de Janeiro: Campus. 1995. 
KRETZER, J. Capacidades de Desenvolvimento como Fonte da Sustentabilidade da Vantagem Competitiva: Uma Contribuição à Visão Baseada em Recursos da Firma. 2002. 253f. Tese (Doutorado em Engenharia de Produção) UFSC, Florianópolis, 2002.

KUPFER, D., HASENCLEVER, L. Economia Industrial: fundamentos teóricos e práticos no Brasil. Rio de Janeiro: Elsevier, 2002.

LAZONICK, W., PRENCIPE, A. Sustained Innovation: Career Engineers, Stock Market, and Theory of Innovative Enterprise. SEWPS - SPRU Electronic Working Paper Series, n.21, August/2004.

LEONARD-BARTON, D. Core capabilities and core rigidities: A paradox in manafing new product development. Strategic Management Journal, Summer Special Issue, v.13, p.111-125

MORAES, A. B., BOMTEMPO,J.V. Capacidade de Inovação e a Construção de Competências na Indústria Química: Uma Análise da Interação Entre a Cadeia Produtiva e o Cliente. In: Simpósio de Gestão da Inovação Tecnológica, 23. 2004, Curitiba. Anais eletrônicos. São Paulo: FIA/USP, 2004. 1 CD.

NONAKA, I., TAKEUCHI, H. Criação de Conhecimento na Empresa - Como as Empresas Japonesas Geram a Dinâmica da Inovação. São Paulo: Editora Campus, 1997.

PENROSE, E. The Theory of the Growth of the Firm. London: Basil Blackwell, 1959.

PORTAL Praxair. Annual Report 2004, em: www.praxair.com. Acesso em: 29/05/2005

PORTER, M. Competitive Strategy. FreePress, Macmillan Publishing Co., 1980.

TEECE D., PISANO, G, SHUEN, A. Dynamic Capabilities and Strategic Management, in Foss, N. (org), Resources, Firms and Strategies, Oxford: Oxford University Press, 1997.

WERNERFELT, B. A Resource Based View of the Firm, Strategic Management Journal, v.5, p.171-180, 1984. cross'

YIN, R.K., Case Study Research: Design and Methods, London and New Delhi: Sage Publications, 1994.

\section{Dados completos do primeiro autor:}

Nome completo: Ana Beatriz Gomes de Mello Moraes

Filiação institucional: Universidade Federal do Rio de Janeiro

Departamento: Escola de Química

Função ou cargo ocupado: Doutoranda

Endereço: Rua Fonte da Saudade 61/208 - Lagoa - Rio de Janeiro - RJ - Brasil - 22471-210

Telefones para contato: 552125381304

e-mail: abgmm@uol.com.br

Recebido para publicação em: 29/12/2005

Aceito para publicação em: 19/03/2006 